
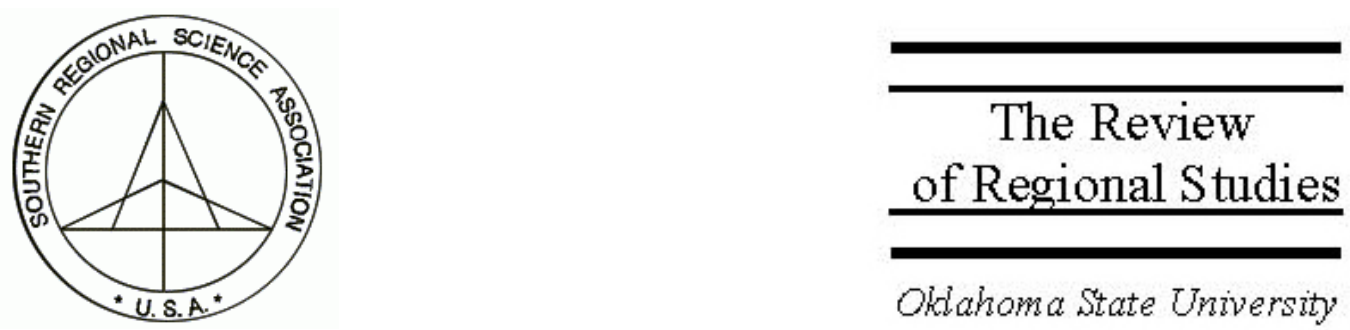

\title{
Factors Affecting the Location of Payday Lending and Traditional Banking Services in North Carolina
}

\author{
Mark L. Burkey \\ Department of Economics and Transportation/Logistics, Quiester Craig Hall, North \\ Carolina A\&T State University, Greensboro, NC 27411, e-mail: burkeym@ncat.edu \\ Scott P. Simkins \\ Department of Economics and Transportation/Logistics, Academy for Teaching and \\ Learning, 313 Dowdy Building, North Carolina A\&T State University, Greensboro, \\ NC 27411,e-mail:simkinss@ncat.edu
}

\begin{abstract}
Payday lending is a relatively new and fast growing segment of the "fringe banking" industry. This paper offers a comparative, descriptive analysis of the location patterns of traditional banks and payday lenders. Utilizing a dataset at the Zip Code Tabulation Area level in North Carolina, we perform negative binomial regressions and find evidence supporting some, but not all, common assertions about the location patterns of both types of institutions. A key finding is that after controlling for many covariates, race is still a powerful predictor of the locations of both banks and payday lenders.
\end{abstract}

Keywords: Payday lending; Fringe banking; Location analysis

JEL classification: C21; L89; R10

The authors would like to thank Reginald Wilkerson for his assistance and Michael Stegman and Robert Faris for their aid in obtaining the data. We also thank Lawrence Morse, two anonymous referees, and the attendees of the 2004 Southern Regional Science Association meetings for helpful comments. 


\section{INTRODUCTION AND BACKGROUND}

During the last decade the U.S. has experienced dramatic growth in the number of non-bank lenders that offer relatively small, short-term, high-interest "payday" loans to credit-constrained borrowers. These loans are simply cash advances backed by a personal check that is held by the payday lender for future deposit or by electronic access to a borrower's bank account. Although no federal data on payday lending is available, industry reports indicate that the payday loan industry has grown from a few hundred outlets in the mid-1990s to more than 20,000 nationwide in 2001, generating between $\$ 10$ and $\$ 20$ billion in annual loan volume and over $\$ 2$ billion in fee revenue. ${ }^{1}$

As this type of non-bank lending has grown, consumer advocacy groups such as the Consumer Federation of America (CFA) and the U.S. Public Interest Research Group (PIRG) have voiced concerns about the lending practices within the industry, citing exorbitant interest rates and predatory lending practices that appear to be targeted at military families and uneducated, minority, or low-income borrowers (CFA/PIRG 2001). In response, these advocacy groups have waged a national campaign to encourage state and federal officials to enact laws regulating the interstate operation of payday lenders, cap finance charges, and limit rollover borrowing. Critics of payday lending also argue that the proliferation and location of payday lenders is evidence of the failure of the Community Reinvestment Act (CRA), originally enacted in 1977 (and revised in 1995), "to encourage depository institutions to help meet the credit needs of the local communities in which they are chartered." ${ }^{2}$ Specifically, they claim that traditional banks have not met their CRA responsibilities, especially in low-income neighborhoods, allowing payday lenders to fill the resulting financial services vacuum. ${ }^{3}$

Against this backdrop, our interest is in exploring what accounts for the growth of payday lending, and in particular where this growth has occurred. Are payday lenders opportunistic predators, locating disproportionately in low-income and minority neighborhoods in order to prey on unsuspecting borrowers, or are they simply niche lenders responding to unmet demand? ${ }^{4}$ Sorting out these competing claims is difficult, but is also critically important for analyzing and making policy decisions related to this

\footnotetext{
${ }^{1}$ See Ernst, Farris, and King (2003); Stegman (2003); Consumer Federation of America and U.S. Public Interest Research Group (2001); and Tanoue (2000). Many of the national estimates of payday loan volume and fee income are produced by Stephens, Inc., a Little Rock, Arkansas, investment firm that researches the payday loan industry.

${ }^{2} 12$ U.S.C. 2901

${ }^{3}$ Avery et al. (1997) fail to find evidence supporting this claim. They conclude that while the number of banking offices in low- and moderate-income areas fell significantly from the late 1980s through the mid-1990s, it is likely "a response to excess capacity" (p. 723) rather than a strategic decision to "benefit more affluent consumers at the expense of lower-income communities" (p. 707).

${ }^{4}$ For an overview of the demand-side factors affecting the use of non-bank lenders, see Kidd (2004) and Elliehausen and Lawrence (2001). Kidd (2004) and Tillett and Handlin (2003) discuss initiatives to bring the unbanked into the banking community.
} 
industry. However, rigorous analyses of the payday lending industry are few in number. Stegman and Faris (2003) provide arguably the most comprehensive analysis of the payday lending industry, but even they ultimately fail to distinguish between demand- and supply-side factors in determining the growth and location of payday lenders. ${ }^{5}$ More research is needed to better understand the factors affecting this industry in order to provide policy makers with better information to guide their policymaking decisions.

Our approach in this paper is to systematically analyze the geographic location of payday lenders in North Carolina in an effort to explore the characteristics that make a geographic area likely to attract this type of lender. In particular, our analysis focuses on differences in demographic and socioeconomic characteristics that are frequently cited by consumer advocacy groups as causal factors in the location of payday lenders. In addition, recognizing that payday lenders serve as both a substitute for and complement to traditional banking services, we compare the results from our geographic analysis of payday lenders to those obtained for traditional banks. We are particularly interested in determining whether there are characteristics of geographic areas that uniquely influence the location of payday lenders relative to traditional banks. The particular questions that we seek to address include the following.

- Is there empirical support for the claims made by consumer advocates such as the CFA regarding the location of payday lenders with regard to race, income, education, public assistance, and military bases?

- Are the factors driving the geographic location of payday lenders different from those underlying the location of traditional banks?

- Is there geographic complementarity or substitution between traditional banks and payday lenders?

While our analysis will not settle the issue of whether payday lenders engage in predatory lending or are simply responding to demand for this type of service, our results shed additional light on current views of the payday lending industry and add to the growing pool of knowledge about this industry.

\section{DATA SET CONSTRUCTION}

To our knowledge, only one study (Kolb 1999) has formally examined the factors that determine the location of payday lenders within a geographic area, but that study focused on only a single city. ${ }^{6}$ State banking officials, payday industry supporters, and consumer advocacy groups also occasionally collect and analyze payday lending industry

\footnotetext{
${ }^{5}$ Stegman and Faris (2003) provide a detailed description of the payday lending industry, particularly in North Carolina.

${ }^{6}$ Kolb found concentrations of payday lenders in minority, working-class, moderate-income neighborhoods in Charlotte, North Carolina.
} 
data, but in most cases these analyses focus on simple data summaries that fail to take into account the interrelationships among factors affecting the location of payday lenders. Our statistical analysis attempts to sort out the factors influencing the location of payday lenders by systematically controlling for socioeconomic and demographic relationships that may be present in the data.

Following Stegman and Faris (2003), our analysis focuses on payday lending and traditional banking data from North Carolina. ${ }^{7}$ Like Kolb, we explore the relationship between the location of banks and payday lenders and demographic/socioeconomic indicators across geographic areas; however, our analysis covers the entire state, dramatically expanding the number of observations and increasing the variability of the data. By including all the regions of the state, we believe that our results better represent the factors that affect the location of payday lenders and traditional banks and provide more general results.

Payday lending data from North Carolina are particularly useful for analyzing the payday lending industry. The North Carolina state legislature enacted legislation in 1997 allowing businesses to engage in "post-dated or delayed deposit check-cashing transactions" in the state but let the legislation expire in August 2001. ${ }^{8}$ As part of the legislative review of this legislation, the North Carolina Commissioner of Banks carried out extensive surveys of licensed North Carolina payday lending and check-cashing businesses in 1999 and 2000 (NC Commissioner of Banks 2001). Data from this survey contain detailed information on the types of operations undertaken by individual companies (e.g., check-cashing only, payday lending only, both) as well as the number and characteristics of payday loan transactions by these companies. ${ }^{9}$ Information from this survey was merged with North Carolina Commissioner of Banks data listing individual check-casher (including payday loan) locations and names to create a master list of businesses providing payday lending services (with locations, by zip code) and operating in North Carolina

\footnotetext{
${ }^{7}$ Given the lack of federal payday lending regulations, state-level data provides the best information about the payday lending industry. Payday lenders are subject to a patchwork of state regulations that differ in their scope and depth. See Consumer Federation of America and U.S. Public Interest Research Group (2001, Appendix A) for a state-by-state listing of payday lending regulations.

${ }^{8}$ As a result, North Carolina currently does not authorize payday lending. The original payday lending provision was included in North Carolina General Statute §53-281. Currently, payday lenders in North Carolina operate under no specific state regulation, acting as affiliates of out-ofstate banks.

${ }^{9}$ This survey data was obtained from Robert Faris on May 29, 2003. Stegman and Faris (2003) use transaction volume data from this survey in their analysis of the payday lending industry. Because this data is collected at the company rather than location level, we use only information on the type of activity in which each location engages.
} 
in $2000 .^{10}$ The resulting list was edited to remove inactive and recently opened locations (within last few months of 2001) using a comprehensive license list (with name and license number) provided to us by the North Carolina Commissioner of Banks.

Data on the location of traditional banks was obtained from the Federal Deposit Insurance Corporation (FDIC) web site, which allows users to query its database for a listing of all banks (and locations) in operation in a particular state and opened before a specific date. ${ }^{11}$ In June, 2003 we obtained location information for all banks operating in North Carolina that were open prior to January 1, 2001. One potential issue is that the banking data does not include banks that were open prior to 2001 but that closed between 2001 and 2003; however, this effect is likely to be minimal. We removed several types of offices that are not consumer banking offices and assigned both banks and payday lenders to the zip codes in which they were located. Note that some zip codes are assigned to a specific building or shopping center. In these cases the institution was assigned to the zip code of the surrounding area to allow for matching with data obtained from the U.S. Census Bureau. Zip codes in both data sets were double-checked and corrected using GIS software.

Our analysis focuses on factors that are correlated with the location of payday lenders and traditional banks, in particular demographic and socioeconomic characteristics of population groups within geographic areas. We obtained 2000 census data on a variety of demographic and socioeconomic variables from the U.S. Census Bureau's Census 2000 Summary File 3 (SF3). ${ }^{12}$ Numerical descriptive statistics summarized at the Zip Code Tabulation Area (ZCTA) level were used. ZCTAs are designed to roughly approximate zip code delivery areas. ${ }^{13}$ The Census Bureau also creates ZCTAs corresponding to parklands, lakes, etc. that are not covered by a zip code; these areas were deleted from the data set. In addition, two zip codes were deleted that contained population but, curiously, no data on incomes and a few other key variables. These two zip codes corresponded to UNC Charlotte and Wake Forest University. Finally, 21 other anomalous ZCTAs reporting fewer than 100 residents were removed from the data set. The final data set contains observations for 760 ZCTAs. Table 1 contains a detailed description of the variables used in our analysis. Ultimately, the Census data was merged with the payday

\footnotetext{
${ }^{10}$ The NC Commissioner of Banks survey was conducted in 2001 and included payday-lending data from 2000. The North Carolina Commissioner of Banks keeps a current listing of licensed check-cashers on its web site (http://www.banking.state.nc.us/cc/checkcas.htm); to develop a list of licensed check-cashers operating in 2000 we used the web service www.archive.org to obtain the list of check casher locations and names that appeared on the North Carolina Commissioner of Banks' web site on February 19, 2001.

${ }_{11}^{11}$ Available at: http://www2.fdic.gov/idasp/main.asp.

${ }^{12}$ SF3 contains detailed information from the census "long form," collected from a 1-in-6 sample and weighted to represent the total population.

${ }^{13}$ ZCTAs sometimes differ from traditional zip codes. Simply put, each ZCTA is built by aggregating census blocks whose address are all of the same ZIP code. In most instances the ZCTA code equals the ZIP Code for an area. For more information, consult http://www.census. gov/geo/ZCTA/zcta.html.
} 
lending and traditional banking data to develop a master data set organized by Zip Code Tabulation Area.

TABLE 1

Variables Used in the Study

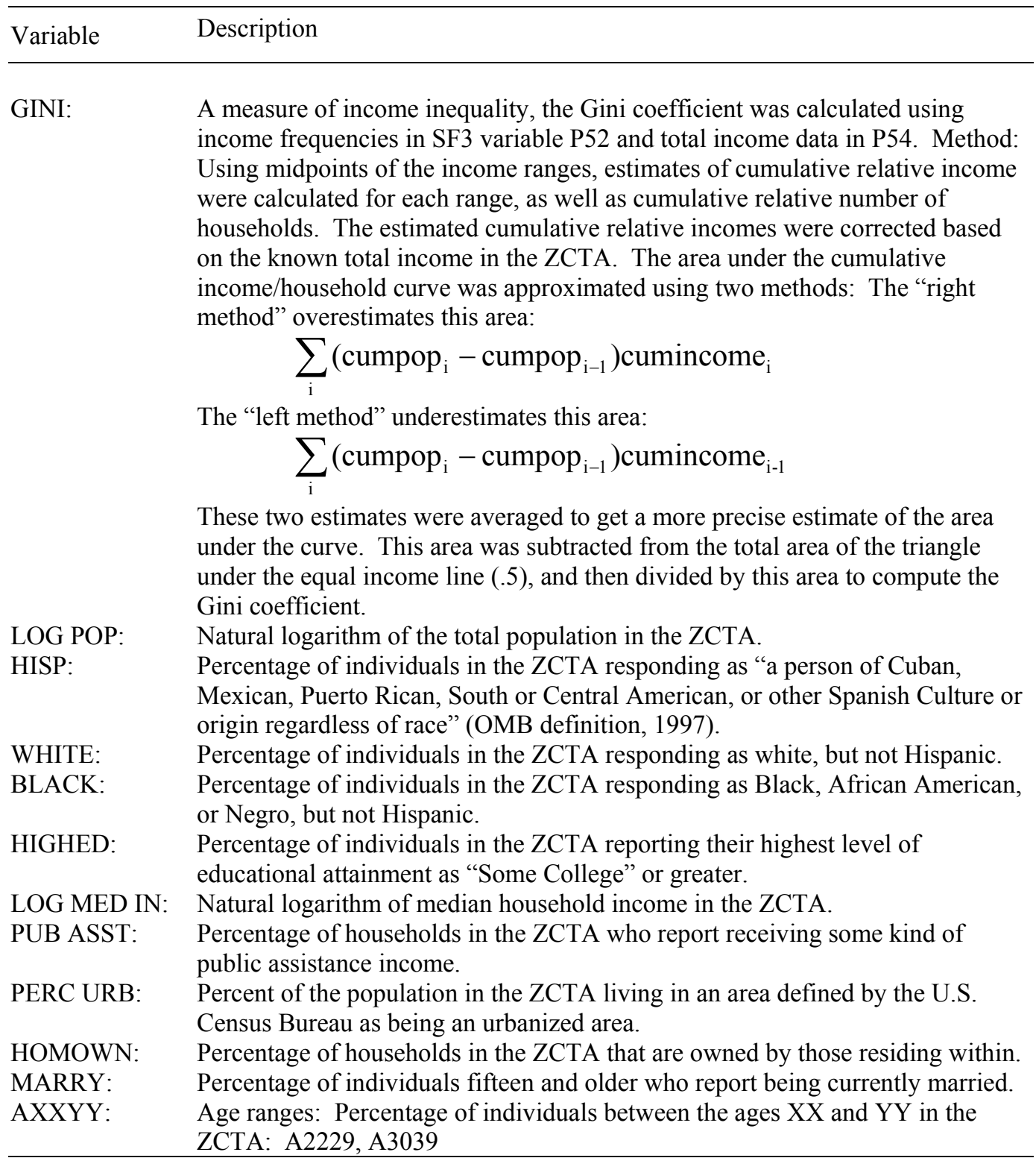




\section{METHODOLOGY}

We use the resulting data set to investigate the relationship between payday lender (or bank) location and demographic/socioeconomic characteristics across ZCTAs in North Carolina. Given that the dependent variable is a count variable, we use Poisson regression to analyze these relationships. Poisson regression relates dependent variable count data (in this case the number of payday lenders or banks located in a ZCTA) to a vector of independent variables, which here includes a variety of demographic and socioeconomic variables. We carry out separate analyses for payday lenders and banks. For small changes in the independent variables, the estimated coefficients of the Poisson regression model represent the proportionate change in the expected number of payday lenders (or banks) in a ZCTA. We estimate a more general extension of the Poisson model, the negative binomial model, to obtain more accurate estimates of the standard errors of the coefficients when there is over-dispersion in the data. ${ }^{14}$ The resulting models are estimated by maximum likelihood techniques using LIMDEP statistical software. In addition, we report two pseudo R-squared measures and an additional goodness of fit measure common for Poisson studies.

Because these data contain explicit spatial relationships, ideally one should use a regression technique that accounts for possible spatial interaction between ZCTAs. At the present time, there is no method for properly estimating spatial regressions with count data (Anselin 2003). Although several attempts have been made to develop approximate solutions, how close these approximations come to the "correct" answer is not well understood. $^{15}$ If a moderate or large amount of spatial correlation exists, the failure to account for this in the estimation will lead to a type of omitted variable bias. Our exploratory analyses of the data suggest that little residual spatial autocorrelation is present and is unlikely to be causing significant bias in the estimates of our models. ${ }^{16}$

\footnotetext{
${ }^{14}$ By definition, the Poisson distribution has a variance equal to its mean. Over-dispersion describes a case in which the variance exceeds the mean.

${ }^{15}$ For example, the Prevention Research Center (part of the Pacific Institute for Research and Evaluation) has developed an iteratively-reweighted GLS method (Gruenewald 2004). Christensen, Møller, and Waagepetersen (2000) developed a Bayesian MCMC approach including relative distance as a covariate.

${ }^{16}$ For example, we calculate the spatial correlation (Moran's I) on the residuals from the negative binomial regressions and examine log-linear OLS models, including a spatial lag variable [see Cameron and Trivedi $(1986,1998)$ and McCullagh and Nelder (1989) for discussions of approximate OLS models to consider when Poisson models become intractable]. Both exercises indicate minor negative spatial correlation, although we cannot determine whether this correlation is statistically significant. The results for the spatial OLS models indicate that the inclusion of a spatial lag variable has little effect on the values of the estimated coefficients in the model. Contact the authors for details.
} 


\section{RESULTS}

Table 2 provides a statistical summary of the top decile of ZCTAs for both payday lenders and banks (per capita). For each ZCTA, the number of payday lenders and banks was divided by the population of the ZCTA and the resulting per-capita values ranked from high to low. Means and standard deviations of a variety of data for the ZCTAs representing the top ten percent of these values are reported in the table. The first column reports statistics for the top ten percent of ZCTAs with the highest density of banks per capita, while the second column reports statistics for the top ten percent of ZCTAs with the highest density of payday lenders per capita. Comparing across columns, note that for the ZCTAs with the highest density of payday lenders, there are fewer banks per capita, a higher percentage of minorities, lower education levels, a higher percentage of people in the military, more people receiving public assistance, a younger population, and more recent immigrants and others who are less likely to speak English compared to the ZCTAs with the highest density of banks. In addition, the table makes it clear that payday lenders are disproportionately located in urban areas, where population densities are highest. These results are consistent with those published by CFA/PIRG (2001) and the popular press. However, simply looking at means of the data gives us an incomplete picture of the role these demographic and socioeconomic variables play in determining the location of payday lenders or banks in a geographic area. To look at the interrelationships among these variables and their effect on the location of payday lenders and banks, we turn now to regression analysis.

The results of the negative binomial regressions are presented in Tables 3 and 4. The pseudo $\mathrm{R}^{2}$ measures in each case are quite high; the models provide an excellent fit to the data. With respect to the estimated coefficients, in both regressions the percentage of housing units within a ZCTA classified as urban and the (log of) population are both positive, but both are statistically significant only in the payday lender equation. The population coefficient estimate for banks is less than one, while the population coefficient for payday lenders is greater than one, suggesting that banks locate in a more decentralized manner while payday lenders concentrate in high population ZCTAs.

In these regressions we also included the (log of the) number of payday lenders in the bank regression and the (log of the) number of banks in the payday lender regression. We wanted to determine whether there was an overall complementarity or substitutability between these financial institutions. ${ }^{17}$ Given that the coefficients on these variables are both positive, each type of institution tends to locate in similar ZCTAs, ceteris paribus. This may reflect an omitted variable, such as the occurrence of shopping or commercial areas within a ZCTA. The GINI coefficient is positive and significant for both regressions. Both types of financial institutions are more likely to be located in areas where

\footnotetext{
${ }^{17}$ For robustness purposes, we ran these regressions omitting these variables. The qualitative nature of the results was unaffected. We used the log form, converting all ZCTAs with values of zero to 0.5 before taking the natural logarithm.
} 
there is more income inequality, ceteris paribus. An ex-post explanation for this finding is that zip codes with retail

TABLE 2

Descriptive Statistics (Top Deciles)

\begin{tabular}{|c|c|c|c|c|}
\hline \multirow[b]{2}{*}{ Variable } & \multicolumn{2}{|c|}{$\begin{array}{c}\text { Top Decile: } \\
\text { Banks per Person* }\end{array}$} & \multicolumn{2}{|c|}{$\begin{array}{l}\text { Top Decile: Payday } \\
\text { Lenders per Person* }\end{array}$} \\
\hline & Mean & Std. Dev. & Mean & Std. Dev. \\
\hline Banks/10,000 Population & 11.90 & 8.70 & 4.06 & 4.36 \\
\hline Payday Lenders/10,000 Pop. & 0.83 & 1.79 & 3.88 & 2.33 \\
\hline \# of Banks & 5.41 & 6.36 & 7.89 & 5.72 \\
\hline \# of Payday Lenders & 1.11 & 2.99 & 7.00 & 4.23 \\
\hline Population & $6,499.00$ & $8,833.95$ & $21,235.09$ & $13,257.39$ \\
\hline GINI Coefficient & 0.45 & 0.05 & 0.45 & 0.05 \\
\hline \% Hispanic (Any Race) & 2.80 & 3.43 & 5.02 & 4.28 \\
\hline \% White (Not Hisp.) & 75.61 & 22.95 & 59.56 & 21.47 \\
\hline \% Black (Not Hisp.) & 19.84 & 23.13 & 32.08 & 20.08 \\
\hline \% Am. Indian (Not Hisp.) & 0.26 & 0.31 & 1.06 & 2.82 \\
\hline \% Asian or PI (Not Hisp.) & 0.62 & 0.97 & 1.06 & 1.09 \\
\hline$\%$ With less than HS Ed. & 22.96 & 12.07 & 26.19 & 7.96 \\
\hline \% High School Grads. & 28.63 & 8.76 & 29.75 & 4.81 \\
\hline \% with Some College & 25.70 & 5.31 & 26.85 & 4.63 \\
\hline \% With 4 Year Degree & 15.47 & 10.17 & 12.06 & 6.11 \\
\hline$\%$ With $>4$ Year Degree & 7.24 & 6.27 & 5.15 & 3.10 \\
\hline Median HH Income & $36,250.05$ & $12,034.06$ & $33,575.17$ & $6,708.17$ \\
\hline Per Capita Income & $20,388.69$ & $9,682.00$ & $17,282.71$ & $3,895.71$ \\
\hline$\%$ In Military & 0.24 & 0.60 & 1.33 & 4.62 \\
\hline \% Labor Force Part. & 59.14 & 9.91 & 62.43 & 6.71 \\
\hline \% Unemployed & 7.33 & 9.33 & 6.68 & 3.23 \\
\hline \% Rec. Public Assistance & 2.93 & 2.63 & 4.07 & 2.04 \\
\hline$\%<$ Poverty Income & 14.19 & 8.70 & 16.60 & 6.29 \\
\hline$\%$ with 1 to 1.5 pov. Inc. & 9.65 & 4.94 & 10.62 & 2.98 \\
\hline$\%$ with 1.5 to 2 pov. Inc. & 10.03 & 5.08 & 10.31 & 2.28 \\
\hline$\%$ in Urban Area & 36.86 & 44.23 & 64.08 & 31.03 \\
\hline$\%$ Households Owned & 55.10 & 16.74 & 57.45 & 12.20 \\
\hline$\%$ Married & 58.54 & 10.32 & 55.51 & 7.95 \\
\hline \% Speak English Poorly & 1.70 & 2.40 & 3.21 & 3.25 \\
\hline$\%$ Age $22-29$ & 10.31 & 4.43 & 11.73 & 3.80 \\
\hline$\%$ Age $30-39$ & 13.81 & 3.78 & 15.01 & 2.32 \\
\hline$\%$ Age $40-49$ & 14.55 & 3.58 & 14.53 & 1.53 \\
\hline$\%$ Age $50-59$ & 12.52 & 3.55 & 10.97 & 2.03 \\
\hline$\%$ Age $60+$ & 22.55 & 7.84 & 17.36 & 4.50 \\
\hline Recent Immigrant, 5 years & 1.21 & 1.57 & 2.34 & 2.62 \\
\hline Recent Immigrant, 5-10 yrs. & 0.57 & 0.96 & 0.99 & 0.96 \\
\hline Population Density & 692.19 & $1,046.07$ & 753.61 & $1,059.90$ \\
\hline
\end{tabular}


TABLE 3

Negative Binomial Regression Results: Banking Model

\begin{tabular}{|c|c|c|c|}
\hline \multicolumn{4}{|c|}{ Dependent Variable: Banks } \\
\hline Variable & $\begin{array}{l}\text { Coefficient } \\
\text { Value }\end{array}$ & $\begin{array}{l}\text { Standard } \\
\text { Error }\end{array}$ & P-value \\
\hline Constant & -5.155 & 3.012 & 0.087 \\
\hline PERC URB & 0.002 & 0.001 & 0.260 \\
\hline LOG POP & 0.859 & 0.049 & 0.000 \\
\hline LOG PAYDAY LENDER & 0.294 & 0.091 & 0.001 \\
\hline GINI & 3.186 & 0.909 & 0.000 \\
\hline BLACK & -0.008 & 0.003 & 0.001 \\
\hline HISP & 0.004 & 0.009 & 0.680 \\
\hline HIGHED & 0.009 & 0.005 & 0.053 \\
\hline LOG MED IN & -0.094 & 0.288 & 0.743 \\
\hline PUB ASST & -0.008 & 0.025 & 0.759 \\
\hline A2229 & -0.017 & 0.007 & 0.016 \\
\hline A3039 & -0.004 & 0.007 & 0.599 \\
\hline HOMOWN & -0.012 & 0.003 & 0.000 \\
\hline MARRY & -0.016 & 0.007 & 0.030 \\
\hline MIL & -0.015 & 0.006 & 0.021 \\
\hline Dispersion & 0.13 & & \\
\hline \multicolumn{4}{|l|}{ Regression Diagnostics: } \\
\hline Number of observations: & \multicolumn{3}{|c|}{760} \\
\hline Log likelihood function:* & \multicolumn{3}{|c|}{-1217.206} \\
\hline Restricted log likelihood:* & \multicolumn{3}{|c|}{-1250.163} \\
\hline Chi squared:* & \multicolumn{3}{|c|}{65.913} \\
\hline Degrees of freedom:* & \multicolumn{3}{|c|}{1} \\
\hline Prob[ChiSqd > value]* & \multicolumn{3}{|c|}{0.0000000} \\
\hline R-squared P: & \multicolumn{3}{|c|}{.8089} \\
\hline R-squared D: & \multicolumn{3}{|l|}{.7438} \\
\hline Overdispersion tests: $\mathrm{g}=\mathrm{mu}(\mathrm{i})$ & \multicolumn{3}{|l|}{2.653} \\
\hline Overdispersion tests: $\mathrm{g}=\mathrm{mu}(\mathrm{i})^{2}$ : & \multicolumn{3}{|l|}{4.212} \\
\hline \multicolumn{4}{|c|}{$\begin{array}{l}\text { * The restricted log likelihoods compare the Poisson model (restricted to } \\
\text { mean=variance) to the negative binomial. The } \chi^{2} \text { test evaluates the } \\
\text { appropriateness of the negative binomial model. }\end{array}$} \\
\hline
\end{tabular}


TABLE 4

Negative Binomial Regression Results: Payday Lending Model

Dependent Variable: Payday Lenders

\begin{tabular}{lccc}
\hline Variable & $\begin{array}{c}\text { Coefficient } \\
\text { Value }\end{array}$ & Standard Error & P-value \\
\hline Constant & 1.040 & 6.209 & 0.867 \\
PERC URB & 0.015 & 0.002 & 0.000 \\
LOG POP & 1.292 & 0.099 & 0.000 \\
LOG BANK & 0.778 & 0.157 & 0.000 \\
GINI & 3.542 & 1.748 & 0.043 \\
BLACK & 0.011 & 0.004 & 0.009 \\
HISP & 0.015 & 0.014 & 0.280 \\
HIGHED & -0.025 & 0.009 & 0.004 \\
LOG MED IN & -1.659 & 0.611 & 0.007 \\
PUB ASST & -0.078 & 0.049 & 0.110 \\
A2229 & 0.018 & 0.012 & 0.147 \\
A3039 & -0.013 & 0.014 & 0.358 \\
HOMOWN & 0.015 & 0.009 & 0.081 \\
MARRY & 0.016 & 0.012 & 0.201 \\
MIL & -0.011 & 0.011 & 0.341 \\
Dispersion & 0.185 & & \\
\hline Regrsion Digg & & &
\end{tabular}

Regression Diagnostics:

Number of observations

760

Log likelihood function*

$-649.074$

Restricted log likelihood*

$-670.448$

Chi squared*

42.75

Degrees of freedom*

1

Prob[ChiSqd > value $]^{*}$

0.0000000

R-squared P:

0.7934

R-squared D:

0.7867

Overdispersion tests: $\mathrm{g}=\mathrm{mu}(\mathrm{i}) \quad 4.54$

Overdispersion tests: $\mathrm{g}=\mathrm{mu}(\mathrm{i})^{2} \quad 7.140$

* The restricted log likelihoods compare the Poisson model (restricted to mean $=$ variance) to the negative binomial. The $\chi^{2}$ test evaluates the appropriateness of the negative binomial model. 
districts in North Carolina often contain pockets of both high and low-income neighborhoods. Thus, areas with many retail establishments (banks, payday lenders, or other) are likely to have high-income inequality.

A particularly interesting result is that even when income, urban-ness, incomeinequality, and education are controlled for, the coefficient on the percentage of blacks within a ZCTA is negative and significant in the bank regression and positive and significant in the payday lender regression. The results are consistent with those presented in Table 1 and support the commonly-held view that payday lenders tend to locate in minority areas (and banks don't). Also striking is how close these coefficients are to 0.01. Because the black race variable is measured in percent, these coefficients tell us that, ceteris paribus, a one percentage point increase in the black population will reduce the number of banks by one percent and increase the number of payday lenders by one percent. Note, however, that the coefficient on the Hispanic variable was not statistically significant in either the bank or payday lending regression models; however, the sign and size of the coefficient on this variable in the payday lender regression is similar to that of the black race variable.

The results for the education variable are as expected. We included the percentage of people in a ZCTA who have a four-year degree or higher education level (HIGHED) in our regression models and find that this variable is positively related to the number of banks in a ZCTA and negatively related to the number of payday lenders.

As a measure of income, we use the natural log of median household income. This variable does not help predict the number of banks in a ZCTA, but shows a negative relationship with the number of payday lenders. Similarly, the percentage of households receiving some type of public assistance income exhibits no relationship with the number of banks located in a ZCTA, but has a negative relationship with the number of payday lenders. These results are consistent with other research that has shown payday lenders locating not in the poorest neighborhoods but neighborhoods populated by the working poor.

The coefficients on the age variables confirmed our beliefs that banks tend to locate in areas with older residents, while payday lenders locate in areas with a younger clientele who are more likely to use their services. The $p$ value of the coefficient of the 22-29 age group variable in the payday lender equation is a bit too high to be confident of a relationship but is signed as expected. The estimates for the home ownership and marriage variables in each regression model, however, are surprising. Their signs are the opposite of what might be expected - both marriage and home ownership have a positive relationship with the number of payday lenders in a ZCTA and a negative effect on the number of banks.

Finally, the signs of the coefficients on the military variable in each regression are noteworthy. A negative and significant coefficient on this variable in the bank regression may indicate that banks are "crowded out" from military areas by the military credit 
unions. It was expected that we would find a positive relationship between the percentage of people in a ZCTA that reported being in the military and the number of payday lenders in that ZCTA. The resulting negative - although statistically insignificant coefficient on the military variable was surprising to us (and runs counter to claims made by the CFA/PIRG) but may also indicate a type of crowding out. Many military bases in North Carolina are surrounded by pawnbrokers and other types of fringe banking services. Since payday lenders are a more recent phenomenon, perhaps they face comparatively more competition than in other areas.

Overall, the regression results suggest that demographic and socioeconomic factors drive the location of payday lenders and traditional banks in quite different ways. In particular, ZCTAs with higher minority concentrations, younger populations, lower median incomes, and lower education levels are associated with a higher number of payday lenders, ceteris paribus, and a lower number of banks.

\section{SUMMARY AND CONCLUSIONS}

At the outset of this paper we posed a series of questions that our analysis would address: (1) whether the analysis supports claims made by consumer advocacy groups about the factors affecting the location of payday lenders, (2) whether the factors driving the location of traditional banks and payday lenders differ, and (3) whether there is spatial complementarity or substitution between traditional banks and payday lenders. In general, our results appear to confirm many of the general claims made about the location of payday lenders - payday lenders tend to locate in urban areas with relatively higher minority concentrations, younger populations, and less-well-educated citizens. However, we find that homeownership and marriage rates are positively related to the number of payday lenders in a ZCTA, while public assistance rates are negatively related to the number of payday lenders. Both of these results run counter to perceived views about payday lenders preying on financially unsophisticated and vulnerable borrowers.

As noted above, the estimated relationship between traditional bank locations and socioeconomic/demographic factors often differs markedly from that of payday lenders, yet there is a strong positive relationship between the number of payday lenders in a ZCTA and the number of traditional banks in the same geographic area. This result suggests that there is a strong complementarity between the quantity of traditional and non-traditional banking services in an area.

Overall, our location analysis is consistent with the claims made by consumer advocacy groups regarding the payday lending industry, although the analysis does not answer the question of whether payday lenders consciously locate in geographic areas to "take advantage" of unsuspecting borrowers or simply to meet the demands of the consumers located there. Clearly, more research needs to be done to sort out the relative roles of demand- and supply-side factors responsible for the growth and location of payday lenders. On the supply-side, consumer groups continue to push for greater payday lending restrictions, while federal regulatory agencies such as the Federal Reserve, the Office 
of the Comptroller of the Currency, and the Office of Thrift Supervision have recently taken legal action against federally-chartered lenders that enlist payday lending partners. In addition, federal agencies are updating CRA regulations in response to these concerns. On the demand side, banks and other private-sector groups are promoting financial literacy programs and experimenting with innovative services that compete directly with those of payday lenders. Whether such initiatives will reduce the role of payday lending and increase the availability of affordable credit to low-income and minority neighborhoods remains to be seen. Our analysis suggests that policymakers should continue to pay attention to the relative geographic distribution of banks and payday lenders and make greater efforts to understand the underlying factors that lead to the disparities that surface in our data. Prudent policy decisions depend critically on this information.

\section{REFERENCES}

Anselin, L., 2003. Personal interview, University of Illinois, Urbana-Champaign, July.

Avery, R.B., R.W. Bostic, P.S. Calem, and G.B. Canner, 1997. "Changes in the Distribution of Banking Offices,” Federal Reserve Bulletin September, 707-725.

Christensen, O.F., J. Møller, and R.P. Waagepetersen, 2000. “Analysis of Spatial Data Using Generalized Linear Mixed Models and Langevin-Type Markov Chain Monte Carlo,” Research Report R-00-2009: Aalborg University.

Consumer Federation of America and U.S. Public Interest Research Group (CFA/PIRG), 2001. "Rent-a-Bank Payday Lending: How Banks Help Payday Lenders Evade State Consumer Protections,” The 2001 Payday Lender Surveys and Report. Available at: http://www.pirg.org/reports/consumer/payday/2001/, March.

Elliehausen, G. and E.C. Lawrence, 2001. "Payday Advance Credit in America: An Analysis of Consumer Demand," Monograph No. 35, Credit Research Center, Georgetown University, McDonough School of Business: Washington, D.C. Available at: http://www.cfsa.net/mediares/Reports/GeorgetownStudy.pdf, March.

Ernst, K., J. Farris, and U. King, 2003. "Quantifying the Economic Cost of Predatory Payday Lending," Center for Responsible Lending Working Paper: Chapel Hill. Available at: http://www.responsiblelending.org/pdfs/CRLpaydaylendingstudy 121803.pdf, January.

Gruenewald, P., 2004. Personal interview, Vancouver, B.C., Canada, June.

Kidd, R.W., 2004. "On the Outside Looking In,” Region Focus Summer, Federal Reserve Bank of Richmond. Available at: http://www.rich.frb.org/pubs/region focus/ summer04/ontheoutside.html, January.

Kolb, A., 1999. "The Spatial Analysis of Bank and Check-Cashing Locations in Charlotte, NC.” University of North Carolina, Center for Community Capitalism Working Paper: Chapel Hill, NC.

North Carolina Commissioner of Banks, 2001. "Report to the General Assembly on the Subject of Payday Lending.” Available at: http://www.banking.state.nc.us/reports/ ccfinal.pdf, January.

Stegman, M.A. and R. Faris, 2003. "Payday Lending: A Business Model that Encourages Chronic Borrowing,” Economic Development Quarterly 17(1), 8-32. 
Tanoue, D., 2000. "Speech Before the Seventh Annual Greenlining Economic Development Summit." Available at: http:/www.fdic.gov/news/news/speeches/archives/ 2000/sp13June00.html, January.

Tillet, D. and L. Handlin, 2003. "Tapping The Potential of the Unbanked - Private Sector Interest Increases,” Chicago Fed Letter 185a (January), Federal Reserve Bank of Chicago. Available at: http://www.chicagofed.org/publications/fedletter/ 2003/ cfljan2003_185a.pdf , January. 